\title{
Evaluation of the Prevalence of Bifid Mandibular Condyle Detected on Cone Beam Computed Tomography Images in a Turkish Population
}

\author{
Evaluación de la Prevalencia de Cóndilo Mandibular Bífido Detectado \\ en Tomografía Computadorizada Cone-Beam en una Población Turca
}

\author{
Kaan Gunduz*; Cansu Buyuk* \& Erol Egrıglu**
}

GUNDUZ, K.; BUYUK, C. \& EGRIOGLU, E. Evaluation of the prevalence of bifid mandibular condyle detected on cone beam computed tomography images in a Turkish population. Int. J. Morphol., 33(1):43-47, 2015.

SUMMARY: The aim of this study was to assess the frequency of the BMC phenomenon in a Turkish patient population. Cone beam computed tomography (CBCT) images of 2634 consecutive patients were retrospectively reviewed. The Chi-squared test was used to determine potential differences in the distribution of BMCs when stratified by sex and side. Among the 2634 patients, 42 (1.7\%) patients were found to have BMC. Of these 42 patients, 22 were female $(0.8 \%)$ and 20 were male $(0.7 \%)$ with age ranging from 29 to 68 years (mean age 47.47). Among the 42 patients, 39 (92.8\%) of the BMCs were unilateral and three (7.1\%) were bilateral. Approximately 24 cases $(53.3 \%)$ were on the right side, and 21 cases (46.6\%) were on the left side. All of the BMCs showed a mediolateral orientation. The mean depth of the BMC was $2.55 \mathrm{~mm}$ in males and $2.68 \mathrm{~mm}$ in females. 2 patients have symptoms whereas the other patients were atraumatic and asymptomatic. BMC is a rare condition that might be more prevalent in the Turkish population. Greater detailed information regarding BMC could be obtained by the widespread use of $\mathrm{CBCT}$ in epidemiological studies.

KEY WORDS: Bifid condyle; Cone beam computed tomography; CBCT images; Temporomandibular joint.

\section{INTRODUCTION}

Bifid mandibular condyle (BMC) is an uncommon anomaly that was first reported by Hrdlicka (1941). BMC, also known as a double-headed condyle, is characterized by a separation of the mandibular condylar head (Hersek et al., 2004). The condylar division ranges from a superficial groove to two different condyles with separate necks (Miloglu et al., 2010).

BMC occurs unilaterally more often than bilaterally in a ratio of approximately $4.4: 1$, and there is no significant difference between age and sex. BMC is diagnosed predominantly as an incidental finding on imaging studies. Although the precise etiology of BMC has not yet been fully elucidated, developmental anomalies, trauma, nutritional disorders, infection, exposure to radiation, genetic factors, teratogenic embryopathy, and surgical condylectomy have been considered as possible causal factors (Neves et al., 2013).
The orientation of the bifid condyle has been classified as anterior-posterior and mediolateral. Szentpétery et al. (1990), suggested that trauma is the cause in cases in which 2 condylar parts are in the sagittal plane, and the persistence of the fibrous septa at the condylar cartilage is the most likely cause in cases in which the parts are in the coronal plane. This description might be accurate for the majority of cases; however, some mediolateral bifid condyles have been reported to follow sagittal fractures through the condylar head (Loh \& Yeo, 1990; Wu et al., 1994). According to Blackwood (1957), the two articulating surfaces of BMC were divided by a groove and could be oriented mediolaterally or anteroposteriorly, characterizing a specific entity.

A review of the literature supports the conclusion that bifid condyles are typically discovered as incidental findings on panoramic radiographs. The sudden increase in the number of cases reported could be attributed to the

\footnotetext{
* Ondokuz Mayis University, Faculty of Dentistry, Department of Dentomaxillofacial Radiology, Samsun, Turkey.

** Ondokuz Mayıs University, Faculty of Arts and Sciences, Department of Statistics, Samsun, Turkey.
} 
widespread use of radiographs (Rehman et al., 2009). The prevalence of BMC has been reported to range from $0.018 \%$ to $1.82 \%$. Although initial screening for the presence of bifid mandibular condyle could be performed using panoramic radiographs, cone beam computed tomography (CBCT) images reveal morphological changes and the exact orientation of the condyle heads. The condition might occur more frequently than is suspected. To assess the frequency of the BMC phenomenon, a study was conducted using CBCT images from 2634 patients.

\section{MATERIAL AND METHOD}

A retrospective study was performed using CBCT imaging of 2634 patients. The sample consisted of 1714 implant patients, 215 TMJ disorder patients, and 705 patients with other disorders (including orthodontic patients, cyst) (Table I). The CBCT images were obtained from the GALILEOS (Sirona Dental Systems, Bensheim, Germany), operating at $98 \mathrm{kVp}, 15-30$ $\mathrm{mA}$ with a field of view of $15 \mathrm{~mm}$ X $15 \mathrm{~mm}$. Realtime reconstruction was performed using an SIRONA Sidexis XG image viewer, and the acquired image data consisted of 12-bit gray scale images with a $0.25 \mathrm{~mm}^{3}$ voxel size.

The CBCT images were evaluated by three dentomaxillofacial radiologists, and all of the images were displayed on a 27 -in. flat-panel color
Table I. Summary of patients and their indications for cone beam CT (CBCT) referral.

\begin{tabular}{llll}
\hline Sex & Male & 1455 & 45.41 \\
& Female & 1179 & 49.54 \\
Total & & 2634 & 47.47 (mean age) \\
Indication for & Implant & 1714 & 53.81 \\
CBCT & Temporomandibular & 215 & 47.35 \\
& joint disorders & & \\
Total & Others & 705 & 41.25 \\
\hline
\end{tabular}

active matrix TFT medical display (Nio Color 3 MP, Barco, Kortrijk, Belgium) under dim lighting conditions. Any conflicts in the reviews were resolved according to the suggestions of the more experienced investigator. The CBCT scans were assessed in all three planes. The mediolateral bifidity was assessed using coronal images parallel to the long axis of the condyle, and the anteroposterior bifidity was assessed using lateral images perpendicular to the long axis of the condyle. The BMC depth was measured by the shortest distance from the line connecting the two highest points of the condyles to the lowest point of the condyles (Fig. 1).

Finally, 45 cases of BMC were found in the 2634 patients. The BMC patients were recalled, and clinical examinations were performed to assess the history of trauma and the presence of TMJ pain and noise. The asymptomatic group consisted of the patients with no TMJ signs and symptoms. The patients who had any conditions that could affect TMJ components such as skeletal abnormalities, TMJ tumors, or other infectious diseases were excluded.

The observed results were analyzed with SPSS 16.0 (Statistical Package for Social Science Inc., Chicago, Illinois, USA). The Chisquared test was used to determine potential differences in the distribution of BMCs when stratified by gender and side. A $p$ value of $<0.05$ was considered statistically significant.

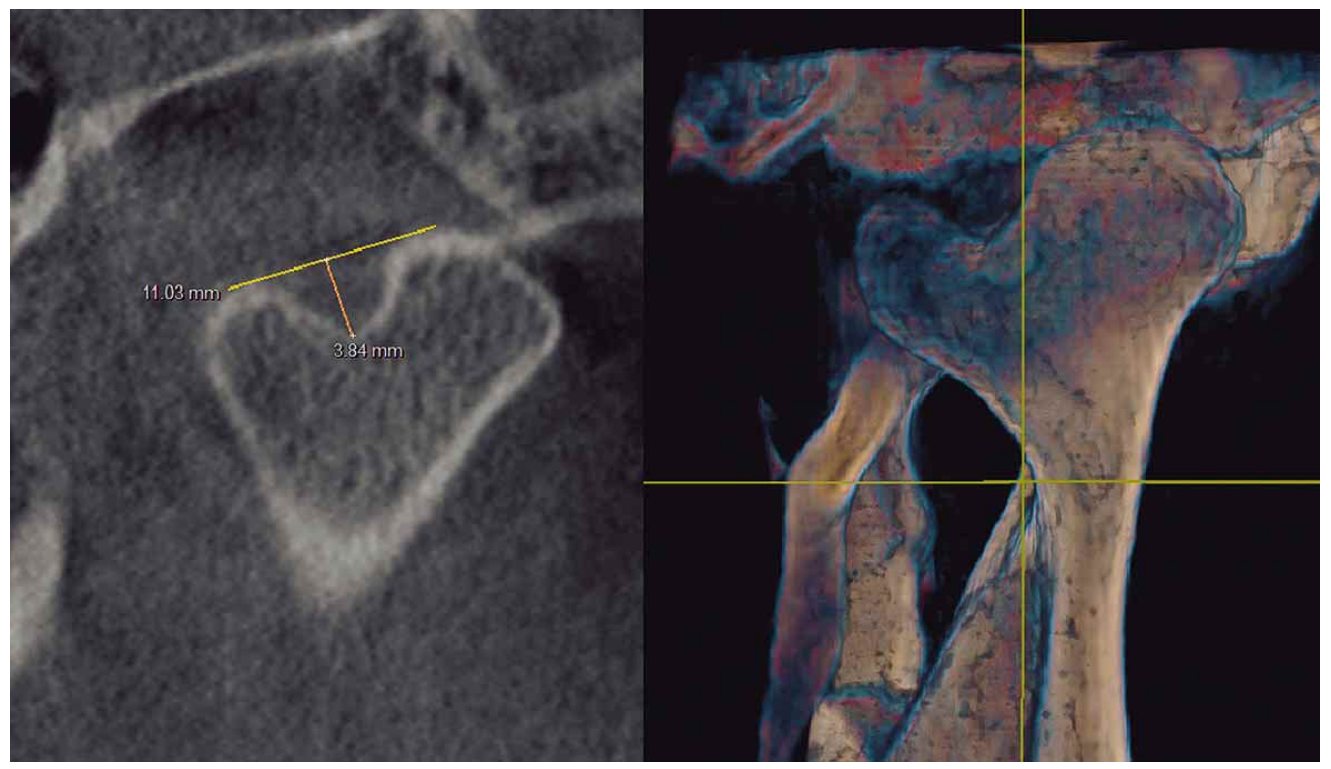

Fig. 1. Measurement of the mediolateral BMC depth on the left and the coronal image of the 3D reconstructed condyle on the right, in the same patient. 


\section{RESULTS}

Among the 2634 patients, $42(1.7 \%)$ patients were found to have BMC. Of these 42 patients, 22 were female $(0.8 \%)$ and 20 were male $(0.7 \%)$; there was no significant sex difference ( $\mathrm{p}>0.05)$. The ages of the patients ranged from 29 to 68 years (mean age 47.47). Among the 42 patients, $39(92.8 \%)$ of the BMCs were unilateral and three $(7.1 \%)$ were

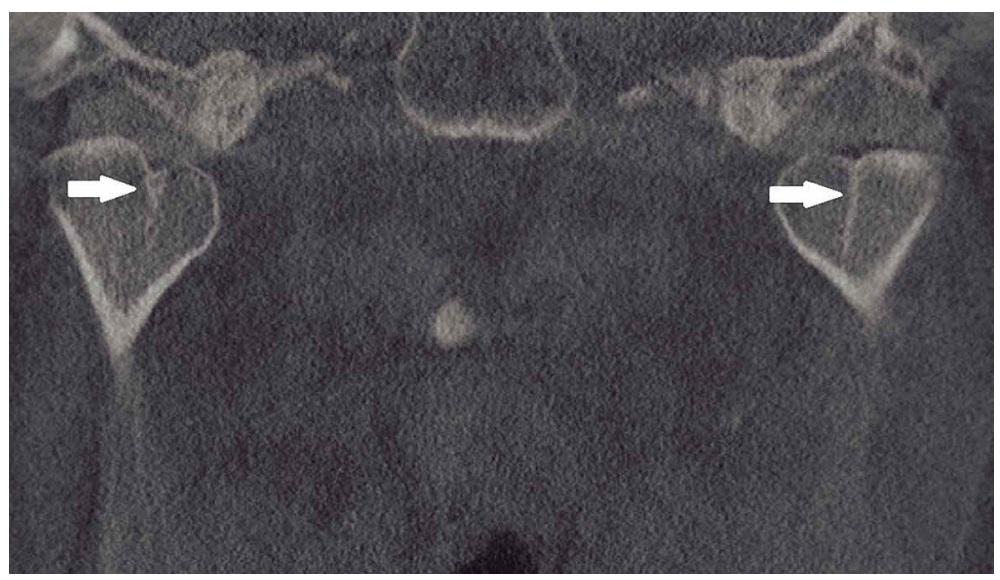

Fig. 2. A coronal CBCT slice shows the bilateral bifid mandibular condyle (arrows).

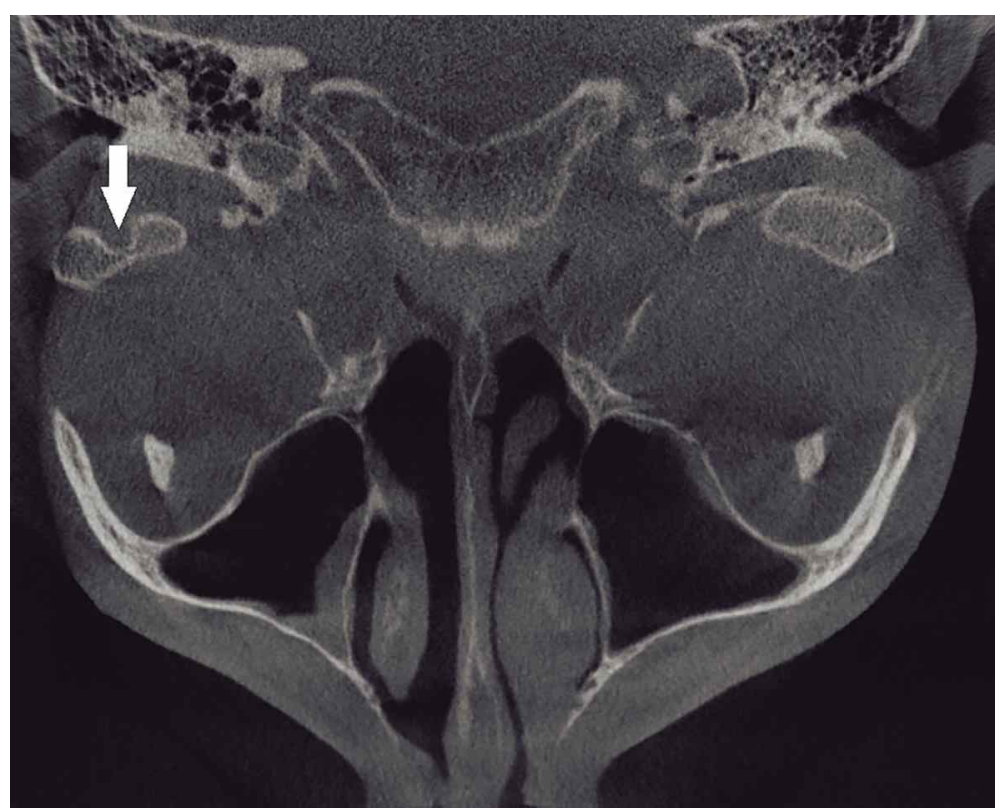

Fig. 3. An axial CBCT slice revealing the duplication of the left mandibular condyle mediolaterally (arrow). bilateral (Fig. 2). In total, 45 BMCs and 39 normal condyles were found in 42 patients. Approximately 24 cases (53.3\%) were on the right side, and 21 cases $(46.6 \%)$ were on the left side; there was no significant difference found $(p>0.05)$. All of the BMCs showed a mediolateral orientation (Fig. 3). The mean depth of the BMC was $2.55 \mathrm{~mm}$ in males and $2.68 \mathrm{~mm}$ in females (p>0.05) (Table II). In the 42 patients with BMCs, two symptomatic patients with a history of traffic accident-caused head trauma and complained only of clicking on mouth opening, whereas the other patients were atraumatic and asymptomatic.

\section{DISCUSSION}

$\mathrm{BMC}$ is a rare condition that is typically discovered as an incidental finding on routine radiographic examinations (Rehman et al.). Although panoramic radiographs and other conventional techniques are adequate in most cases, CBCT allows for the detailed visualization of condylar morphology by preventing osseous superimposition (Menezes et al., 2008; Sahman et al., 2012). A lower exposure dose is a significant advantage of CBCT in comparison with multislice computed tomography and conventional tomography (Neves et al.). To impede misinterpretation of BMC prevalence, CBCT was used as the imaging technique in this study.

Many epidemiological studies regarding BMC have been conducted. Menezes et al., found nine $(0.018 \%)$ cases of BMC from 50,080 panoramic radiographs in a Brazilian population, whereas Miloglu et al. (2010), found $32(0.3 \%)$ cases of BMC from 10,200 panoramic radiographs, and Sahman et al., found 98 $(0.52 \%)$ cases of BMC from 18,798 radiographs in a Turkish population. According to these distinctive results, Sahman et al. (2011), hypothesized that BMC might be more frequent

Table II. Characteristics of BMC patients according to sed and variety, and the number of condyles according to the side

\begin{tabular}{|c|c|c|c|c|c|c|c|}
\hline \multirow{2}{*}{ Patients } & \multicolumn{2}{|c|}{ Uni- or bilateral } & \multicolumn{2}{|c|}{ BMC side } & \multirow{2}{*}{$\begin{array}{c}\text { Depth of } \\
\text { BMC } \\
(\mathrm{mm})\end{array}$} & \multicolumn{2}{|c|}{$\begin{array}{l}\text { Orientation of the bifid } \\
\text { mandibular condyle }\end{array}$} \\
\hline & Unilateral & Bilateral & Right & Left & & Mediolateral & Anteroposterior \\
\hline Male & 19 & 1 & 11 & 10 & 2.55 & 21 & -- \\
\hline Female & 20 & 2 & 13 & 11 & 2.68 & 24 & --- \\
\hline
\end{tabular}


in the Turkish population. In 2013, Cho \& Jung, found 37 $(0.50 \%)$ cases from 7,424 CBCT images and a total of 44 BMCs $(0.30 \%)$ from 14,848 condyles. In the same year, Neves et al., performed a retrospective study using CBCT records and panoramic radiographs of 350 patients and found BMCs in 4 cases (1.1\%). Sahman et al. (2011), found 10 (1.82\%) patients with 13 BMCs in 550 computed tomography images. Caglayan \& Tozoglu (2012), found that $2.9 \%$ of patients had a bifid condyle as an incidental TMJ finding on CBCT scans. The prevalence of BMCs in this study was similar with the prevalence reported in previous studies that utilized panoramic radiographs and $\mathrm{CBCT}$ in the Turkish population; the prevalence was higher than that in other populations. The discrepancies could reflect the diversity of imaging modalities, race, and sample size.

According to the literature, the occurrence of BMC does not show a predilection for sex or any particular age group (Miloglu et al.; Menezes et al.; Sahman et al., 2011, 2012; Cho \& Jung). According to Loh and Yeo, the majority of patients were over 20 years old, which is in agreement with our findings. Although Cho \& Jung and Menezes et al., found a female-male ratio of 3.1:1 and 3.5:1, respectively, Antoniades et al. (2004), found a male-female ratio of approximately 1.5:1, and Miloglu et al., and Sahman et al. (2012), found a closer $\mathrm{BMC}$ prevalence between women and men. With the ratio of female-male patients examined in this study, there was no statistically significant difference between female and male prevalence $(\mathrm{p}>0.05)$.

To obtain precise information regarding the orientation of BMCs, 2D conventional radiographs were insufficient and 3D imaging techniques were useful (Sahman et al., 2011). Although Dennison et al. (2008), expressed that only the anteroposterior division of a condyle is a "true" bifid condyle, $\mathrm{BMC}$ has been generally considered in cases in which a condyle arises to be duplicated anteroposteriorly or mediolaterally (Cho \& Jung). In our study, all of the BMCs showed a mediolateral orientation. In this study, no condyle showed anteroposterior bifidity, and it was hypothesized that anteroposterior bifidity presented concomitant to mediolateral orientation and that this classification is not sufficient for all cases; a BMC could be oriented in an oblique position that is not anteroposterior or mediolateral. A certain diagnosis regarding the exact pattern of a BMC is not possible with conventional radiographic techniques, and clinicians could misdiagnose the orientation of condyles in panoramic radiographs. Shriki et al. (2005) proposed the hypothesis that a bifid condyle with mediolateral heads was a developmental phenomenon rather than a result of trauma, and our results supported this claim. Many studies have reported that the majority of patients showing mediolateral bifidity had no traumatic history (Shriki et al.; Plevnia et al., 2009; Ramos et al., 2006; Acikgöz, 2006; Melo et al., 2012), although Melo et al., reported a very rare case of a nontraumatic anteroposterior bifid condyle. In connection with BMC orientation, it has been suggested that a sagittal split with an anteroposterior orientation was associated with a traumatic event (Szentpétery et al.; Shriki et al.; Plevnia et al.; Forman \& Smith, 1984; Gunduzet al., 2010). Other authors have demonstrated that fractures of the mandibular condyle could result in mediolateral and anteroposterior BMCs.

In the literature review, the majority of the BMC cases were unilateral, and a bilateral pattern was rare (Miloglu et al.; Neves et al.; Menezes et al.; Sahman et al., 2011, 2012; Cho \& Jung). In our study, 39 (92.8\%) of the BMCs were unilateral, and three (7.1\%) were bilateral, which is consistent with previous study findings. Although most studies reported that BMCs involved the left side more often than the right side (Menezes et al.; Sahman et al., 2011, 2012; Cho \& Jung). Miloglu et al., showed a predilection for the right side. In our study, 24 cases (53.3\%) were on the right side, and 21 cases $(46.6 \%)$ were on the left side, and the difference was not statistically significant ( $\mathrm{p}>0.05)$.

Although the exact etiology of BMC is not yet well defined, the most likely cause is a history of trauma (Sahman et al., 2012; Antoniades et al., 1993). In a study by Neves $e t$ al., all of the individuals with bifid mandibular condyle had a history of childhood trauma. Many studies have shown that the majority of the patients had no history of trauma or TMJ symptoms (Miloglu et al.; Loh \& Yeo; Antoniades et al., 2004). According to Cho \& Jung, there was no significant difference in the distribution of clinical symptoms in patients with normally shaped condyles and patients with BMCs, which supported the hypothesis that BMC does not stimulate TMJ symptoms. In this study, the two patients who had a history of trauma and clicking on mouth opening and the atraumatic and asymptomatic patients showed no significant differences in the distribution of clinical symptoms between the BMC sides ( $>0.05$ ), which suggested that BMC does not provoke TMJ symptoms.

GUNDUZ, K.; BUYUK, C. \& EGRIOGLU, E. Evaluación de la prevalencia de cóndilo mandibular bífido detectado en tomografía computadorizada cone-beam en una población turca. Int. J. Morphol., 33(1):43-47, 2015.

RESUMEN: El objetivo de este estudio fue evaluar la frecuencia del fenómeno CMB en una población de pacientes de Turquía. Se revisaron imágenes consecutivas de tomografía computarizada (CBCT) de 2.634 pacientes retrospectivamente. Se utilizó la prueba de Chi-cuadrado para determinar las posibles diferencias en la distribución de CMB estratificado por sexo y lado. Entre los 2.634 pacientes, se encontró que $42(1,7 \%)$ pacientes tenían CMB. De estos 42 pacientes, 22 eran mujeres $(0,8 \%)$ y 20 eran varones $(0,7 \%)$, con edades entre 29 a 68 años (prome- 
dio edad 47,47). Entre los 42 pacientes, $39(92,8 \%)$ del CMB fueron unilaterales y tres $(7,1 \%)$ fueron bilaterales. Aproximadamente 24 casos $(53,3 \%)$ estaban en el lado derecho, y 21 casos $(46,6 \%)$ estaban en el lado izquierdo. Todas las $\mathrm{CMB}$ mostraron una orientación mediolateral. La profundidad media de la CMB era 2,55 mm en los hombres y 2,68 $\mathrm{mm}$ en las mujeres. Dos de los pacientes presentaron síntomas, mientras que en el resto de los pacientes no presentó trauma ni síntomas. CMB es una afección poco común que podría ser más frecuente en la población turca. Mayor información y detalle sobre CMB se podría obtener en estudios epidemiológicos con el uso generalizado de CBCT.

PALABRAS CLAVE: Cóndilo bífido; Tomografía computadorizada de haz cónico; Imágenes CBCT; Articulación temporomandibular.

\section{REFERENCES}

Acikgöz, A. Bilateral bifid mandibular condyle: a case report. J. Oral Rehabil., 33(10):784-7, 2006.

Antoniades, K.; Karakasis, D. \& Elephtheriades, J. Bifid mandibular condyle resulting from a sagittal fracture of the condylar head. Br. $J$. Oral Maxillofac. Surg., 31(2):124-6, 1993.

Antoniades, K.; Hadjipetrou, L.; Antoniades, V. \& Paraskevopoulos, K. Bilateral bifid mandibular condyle. Oral Surg. Oral Med. Oral Pathol. Oral Radiol. Endod., 97(4):535-8, 2004.

Blackwood, H. J. The double-headed mandibular condyle. Am. J. Phys. Anthropol., 15(1):1-8, 1957.

Caglayan, F. \& Tozoglu, U. Incidental findings in the maxillofacial region detected by cone beam CT. Diagn. Interv. Radiol., 18(2):159-63, 2012.

Cho, B. H. \& Jung, Y. H. Nontraumatic bifid mandibular condyles in asymptomatic and symptomatic temporomandibular joint subjects. Imaging Sci. Dent., 43(1):25-30, 2013.

Dennison, J.; Mahoney, P.; Herbison, P. \& Dias, G. The false and the true bifid condyles. Homo, 59(2):149-59, 2008.

Forman, G. H. \& Smith, N. J. Bifid mandibular condyle. Oral Surg. Oral Med. Oral Pathol., 57(4):371-3, 1984.

Gunduz, K.; Avsever, H.; Karacayli, U. Bilateral bifid condylar process. Int. J. Morphol., 28(3):941-4, 2010.

Hersek, N.; Ozbek, M.; Tas sar, F.; Akpinar, E. \& Firat, M. Bifid mandibular condyle: a case report. Dent. Traumatol., 20(3):184-6, 2004

Hrdlicka, A. Lower jaw: double condyles. Am. J. Phys. Anthropol., 28:7589, 1941.

Loh, F. C. \& Yeo, J. F. Bifid mandibular condyle. Oral Surg. Oral Med. Oral Pathol., 69(1):24-7, 1990

Melo, S. L.; Melo, D. P.; Oenning, A. C.; Haiter-Neto, F.; Almeida, S. M. $\&$ Campos, P. S. Magnetic resonance imaging findings of true bifid mandibular condyle with duplicated mandibular fossa. Clin Anat., 25(5):650-5, 2012.
Menezes, A. V.; de Moraes Ramos, F. M.; de Vasconcelos-Filho, J. O.; Kurita, L. M.; de Almeida, S. M. \& Haiter-Neto, F. The prevalence of bifid mandibular condyle detected in a Brazilian population. Dentomaxillofac. Radiol., 37(4):220-3, 2008.

Miloglu, O.; Yalcin, E.; Buyukkurt, M.; Yilmaz, A. \& Harorli, A. The frequency of bifid mandibular condyle in a Turkish patient population. Dentomaxillofac. Radiol., 39(1):42-6, 2010.

Neves, F. S.; Ramírez-Sotelo, L. R.; Roque-Torres, G.; Resende Barbosa, G. L.; Haiter-Neto, F. \& de Freitas, D. Q. Detection of bifid mandibular condyle by panoramic radiography and cone beam computed tomography. Braz. J. Oral Sci., 12(1):16-9, 2013.

Plevnia, J. R.; Smith, J. A. \& Stone, C. G. Bifid mandibular condyle without history of trauma or pain: report of a case. J. Oral Maxillofac. Surg., 67(7):1555-61, 2009

Ramos, F. M.; Filho, J. O.; Manzi, F. R.; Bóscolo, F. N. \& Almeida, S. M. Bifid mandibular condyle: a case report. J. Oral Sci., 48(1):35-7, 2006.

Rehman, T. A.; Gibikote, S.; Ilango, N.; Thaj, J.; Sarawagi, R. \& Gupta, A. Bifid mandibular condyle with associated temporomandibular joint ankylosis: a computed tomography study of the patterns and morphological variations. Dentomaxillofac. Radiol., 38(4):239-44, 2009.

Sahman, H.; Sisman, Y.; Sekerci, A. E.; Tarim-Ertas, E.; Tokmak, T. \& Tuna, I. S. Detection of bifid mandibular condyle using computed tomography. Med. Oral Patol. Oral Cir. Bucal., 17(6):e930-4, 2012.

Sahman, H.; Sekerci, A. E.; Ertas, E. T.; Etoz, M. \& Sisman, Y. Prevalence of bifid mandibular condyle in a Turkish population. J. Oral Sci., 53(4):433-7, 2011.

Shriki, J.; Lev, R.; Wong, B. F.; Sundine, M. J. \& Hasso, A. N. Bifid mandibular condyle: $\mathrm{CT}$ and MR imaging appearance in two patients: case report and review of the literature. A. J. N. R. Am. J. Neuroradiol., 26(7):1865-8, 2005.

Szentpétery, A.; Kocsis, G. \& Marcsik, A. The problem of the bifid mandibular condyle. J. Oral Maxillofac. Surg., 48(12):1254-7, 1990.

Wu, X. G.; Hong, M. \& Sun, K. H. Severe osteoarthrosis after fracture of the mandibular condyle: a clinical and histologic study of seven patients. J. Oral Maxillofac. Surg., 52(2):138-42, 1994.

\section{Correspondence to: \\ Dt. Cansu Buyuk \\ Ondokuz Mayıs University \\ Faculty of Dentistry \\ Department of Dentomaxillofacial Radiology \\ 55139 Samsun \\ TURKEY}

Email: cansubuyuk@yahoo.com

Received: 12-05-2014

Accepted: 05-11-2014 